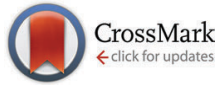

Cite this: J. Mater. Chem. C, 2015, 3, 9551

Received 3rd June 2015,

Accepted 13th August 2015

DOI: $10.1039 / c 5 t c 01624 j$

www.rsc.org/MaterialsC

\title{
Synergetic enhancement of organic solar cell thermal stability by wire bar coating and light processing $\dagger$
}

\author{
Ching-Hong Tan, ${ }^{\text {ac }}$ Him Cheng Wong, ${ }^{\text {cde }}$ Zhe Li, ${ }^{\text {abc }}$ David G. Bucknall, \\ James R. Durrant ${ }^{\star a b c}$ and João T. Cabral ${ }^{\star c d}$
}

\begin{abstract}
We demonstrate that organic solar cells can exhibit different morphological and performance stability under thermal stress depending upon the processing technique employed, without compromising initial device efficiency. In particular, we investigate benchmark PCDTBT:PC ${ }_{60}$ BM solar cells fabricated by wire bar coating (a technique attractive for commercial manufacture) and the more widely employed, lab scale, technique of spin coating. For this system, wire bar deposition results in superior device stability, with lifetime improvements in excess of 20 -fold compared to spun cast devices. Neutron reflectivity reveals that the enhanced $\mathrm{PC}_{60} \mathrm{BM}$ segregation to the top interface in the slower, wire bar, casting process is likely responsible for the hindered $\mathrm{PC}_{60} \mathrm{BM}$ nucleation at tens of $\mathrm{nm}$ length scale, characterized by atomic force microscopy (AFM), and thus enhanced morphological stability. Modest light exposure of the active layer (at approximately $10 \mathrm{~mW} \mathrm{~cm}^{-2}$ ), known to reversibly photo-oligomerize fullerenes and thus impart morphological stability, is found to further improve device stability by a factor of 10 . The combined effects of wire bar coating and light processing are highly synergetic, resulting in solar cells which are overall 200 times more stable than devices prepared by spin casting without light processing.
\end{abstract}

\section{Introduction}

Organic solar cells (OSCs), generally comprising a nanostructured thin film of a conjugated polymer donor and a fullerene derivative acceptor, provide an increasingly attractive technology for energy harvesting and solar energy conversion. While single-junction solar cells are now approaching $10 \%$, often regarded as the threshold for commercialization, ${ }^{1-4}$ significant

\footnotetext{
${ }^{a}$ Department of Chemistry, Imperial College London, London SW7 2AZ, UK

${ }^{b}$ SPECIFIC, College of Engineering, Swansea University, Baglan Bay Innovation, Knowledge Centre, Central Avenue, Baglan SA12 7AX, UK

${ }^{c}$ Centre for Plastic Electronics, Imperial College London, SW7 2AZ, UK.

E-mail: j.cabral@imperial.ac.uk, j.durrant@imperial.ac.uk

${ }^{d}$ Department of Chemical Engineering, Imperial College London, London SW7 2AZ, UK

${ }^{e}$ Engineering Product Development, Singapore University of Technology and Design, 8 Somapah Road, 487372 Singapore, Singapore

${ }^{f}$ Materials Science and Engineering, Georgia Institute of Technology, 801 Ferst Dr NW, Atlanta, GA 30332, USA

$\dagger$ Electronic supplementary information (ESI) available: SC and WBC drying kinetics measurements. UV-vis absorption spectra of SC and WBC PCDTBT:PC ${ }_{60} \mathrm{BM}$ blend layers. PL spectra of SC and WBC blended layers and their respective PCDTBT neat layers. $\mathrm{EQE}$ of blend devices deposited by SC and WBC techniques. Optical microscopy images of the blend layer deposited by $\mathrm{SC}$ and $\mathrm{WBC}^{\circ}$ on $\mathrm{SiO}_{x}$ (as cast) and PEDOT:PSS (at $80{ }^{\circ} \mathrm{C}$ and $140{ }^{\circ} \mathrm{C}$ thermal annealing temperature). Data supporting this publication can be obtained on request from polymer-microfluidics@imperial.ac.uk. See DOI: 10.1039/c5tc01624j
}

challenges remain in attaining the long-term OSC stability required for commercial application ${ }^{5}$ and ensuring low cost, reliable manufacturing and scale-up. Our paper considers the role of representative photoactive layer deposition and processing approaches on the morphological and performance stability of OSC under $80{ }^{\circ} \mathrm{C}$ thermal stress, relevant to device operation conditions.

The vast majority of highly efficient polymer/fullerene OSCs reported to date has been fabricated by spin coating (SC). ${ }^{6-8}$ This is intrinsically a batch technique, and unsuitable for large scale manufacturing. ${ }^{7}$ Further, SC typically wastes $90 \%$ of precursor solution and is incompatible with device patterning. A number of alternative deposition methods for solution processable OSCs have been proposed, including spray drying, ${ }^{9}$ flow and wire bar coating (WBC), which appear compatible with industrial roll-to-roll (R2R) manufacturing. ${ }^{10,11} \mathrm{WBC}$, focused on herein, employs a wire wound bar that translates over the substrate at a well-defined height, depositing the active layer solution; this processing technique allows control of velocity and temperature profiles with minimal waste and high reproducibility. ${ }^{11,12}$ The impact of solution deposition in OSC morphology and performance is known to be significant, ${ }^{10,13-16}$ related in part to the different flow fields and temporal drying profiles experienced during film formation. SC is generally faster, while WBC is comparatively slower and can lead to the development of 
travelling fronts, surface templating, structural rearrangement and component stratification. ${ }^{7,10,11,17}$ During the photoactive layer film formation process, the development of a nano-phase separated bicontinuous morphology (a 'bulk heterojunction') is required for device performance, and in particular for charge generation and carrier transport. ${ }^{2}$ Film deposition, in addition to subsequent thermal, ${ }^{18}$ solvent ${ }^{19}$ and light processing, ${ }^{20,21}$ plays a key role in engineering a functional nanostructured photoactive layer.

Solar cell operation inherently involves the cyclic temperature and illumination variations which occur in the environment. Prolonged thermal annealing has been found to cause degradation of OSC device efficiency, which has been related to the diffusion, aggregation and large-scale crystallization of the fullerene derivatives, coarsening of the nanophases and delamination of electrodes, amongst others. ${ }^{13,18,22}$ Hence, a thermally stable (either thermodynamically-stable or 'frozen' out-of-equilibrium) morphology is desirable for long-term OSC device performance.

Both micron- and nano-scale [6,6]-phenyl-C61-butyric-acidmethyl-ester $\left(\mathrm{PC}_{60} \mathrm{BM}\right)$ crystallization have been extensively documented both in neat films and when blended with a donor polymer, ${ }^{23-29}$ and found to be dependent on solution deposition method and solvent, substrate, polymer matrix and regioregularity, polymer composition profile, and subsequent annealing temperature. For instance, slow evaporation of neat $\mathrm{PC}_{60} \mathrm{BM}$ solutions was found to favour micron-size crystals, by contrast with nanocrystals formed by faster spin coating, ${ }^{23}$ highlighting the importance of evaporation and fullerene self-organization kinetics in film formation. The mechanism of $\mathrm{PC}_{60} \mathrm{BM}$ crystallization, including overall crystal size and crystal structure, has been shown to be mediated by interaction with the polymer matrix and templated by the substrate (mica, in one study). ${ }^{27}$ Micron- and nano-scale $\mathrm{PC}_{60} \mathrm{BM}$ crystal formation can happen simultaneously or exclusively through a competitive bimodal crystallization process. ${ }^{29}$ Abundant formation of large crystals generally corresponds to a scarcity of nano-crystals and vice versa. ${ }^{20,21,27,29}$

Blend films of donor polymers with $\mathrm{PC}_{60} \mathrm{BM}$, the most widely studied acceptor for OSCs, often exhibit only limited thermal stability, depending on the donor polymer employed. ${ }^{30-32}$ For example, our recent thermal stability studies of OSC's employing the benchmark donor polymer poly[[9-(1-octylnonyl)-9H-carbazole2,7-diyl]-2,5-thiophenediyl-2,1,3-benzothiadiazole-4,7-diyl-2,5thiophenediyl] (PCDTBT) showed a retention of only $65 \%$ of the initial device performance after $130 \mathrm{~h}$ of thermal annealing at $80{ }^{\circ} \mathrm{C} .{ }^{21}$ Strategies to enhance OSC thermal stability have focused on chemically modifying the polymer donor, additives or fullerenes (recently reviewed by Rumer and Mcculloch $^{33}$ ). For instance, enhanced OSC thermal stability has been recently demonstrated by crosslinking the polymer donor (achieved 0.9 internal quantum yield), ${ }^{34}$ copolymer (power conversion efficiency (PCE) of $4.7 \%$ after $72 \mathrm{~h}$ of $150{ }^{\circ} \mathrm{C}$ thermal annealing), ${ }^{35}$ functionalization of donor polymer (PCPDTBT) side chain ${ }^{36}$ and by UV-crosslinking the fullerene phase ${ }^{37}$ as well as the addition of film additive to improve OSC thermal stability. ${ }^{38}$ We have recently reported ${ }^{20,21}$ that modest white light illumination $\left(<10 \mathrm{~mW} \mathrm{~cm}{ }^{-2}\right)$ prior to thermal annealing, can also result in the OSC thermal stability increasing $\sim 10$ fold due to a lightinduced fullerene oligomerization process. ${ }^{39}$ This process bonds at least two $\mathrm{PC}_{60} \mathrm{BM}$ molecules and, beyond a certain threshold, effectively suppresses fullerene crystallization during thermal annealing, which in turn results in an enhanced device thermal stability. $\mathrm{We}^{21}$ and others ${ }^{40}$ have shown that this light induced morphological stabilization effect is observable across $\mathrm{PC}_{60} \mathrm{BM}$ mixtures with a range of benchmark donor polymers including P3HT, DPP-TT-T and PTB7, and can also be induced by the addition of chemically synthesized fullerene dumbbells. ${ }^{41}$ Unexpectedly, we found that only the nucleation - but not the growth - rate of $\mathrm{PC}_{60} \mathrm{BM}$ macroscopic crystals is affected by light exposure. Fullerene nucleation appears thus to be effectively frustrated by $\mathrm{PC}_{60} \mathrm{BM}$ oligomerization, with approximately $20 \%$ conversion fully suppressing crystallization. Further, light induced oligomerization was found to be reversible,$^{21}$ as the fullerene-fullerene bond can be fully dissociated (dissociation energy approx. $1 \mathrm{eV})$ at elevated temperatures $\left(150{ }^{\circ} \mathrm{C}\right.$ for 60 minutes). We also noted a significant role of the substrate on the $\mathrm{PC}_{60} \mathrm{BM}$ crystallization in the film and its thermal stability: micron-sized crystallization is significant on $\mathrm{SiO}_{x}$ but infrequent on poly(3,4-ethylenedioxythiophene):poly(styrene sulfonate) (PEDOT:PSS) under identical annealing conditions. Instead, nano-sized crystal formation is observed on PEDOT:PSS. Prior illumination was found to be effective in suppressing both micro and nano-sized crystallization under thermal annealing. ${ }^{21}$

With these ideas in mind, we now directly compare the industrially relevant film processing technique of WBC to the benchmark SC process in terms of film morphology, OSC device performance and thermal stability. In addition, we implement the previously established light-induced thermal stability enhancement ${ }^{20,21}$ on WBC and SC devices to evaluate the combined effects of the two processing approaches, and demonstrate an overall (synergetic) lifetime enhancement of approximately $200 \times$ for PCDTBT:PC ${ }_{60} \mathrm{BM}$ OSCs.

\section{Experimental}

\section{Device fabrication and thermal stability studies}

PCDTBT $\left(M_{\mathrm{w}} \sim 21.6 \mathrm{~kg} \mathrm{~mol}{ }^{-1}\right.$; PDI $\left.\sim 5.5\right)$ and $\mathrm{PC}_{60} \mathrm{BM}$ were supplied by 1-Materials, Inc. and Nano-C, Inc. respectively. A solution of PCDTBT: $\mathrm{PC}_{60} \mathrm{BM}$ in $1: 2$ ratio was dissolved in $\mathrm{CB}$ solvent with a total solution concentration of $25 \mathrm{~g} \mathrm{~L}^{-1}$. This solution was stirred for $24 \mathrm{~h}$ in $\mathrm{N}_{2}$ environment followed by filtration through a $0.2 \mu \mathrm{m}$ filter prior to applying.

ITO glass substrates were cleaned with acetone, iso-propyl alcohol and deionized water sequentially and underwent an oxygen plasma treatment at $100 \mathrm{~W}$ for $7 \mathrm{~min}$. PEDOT:PSS layers of $35 \mathrm{~nm}$ were spin coated on the glass substrates followed by annealing at $150{ }^{\circ} \mathrm{C}$ for $20 \mathrm{~min}$ in air. The filtered PCDTBT and $\mathrm{PC}_{60} \mathrm{BM}$ solution was deposited on the substrates by spin coating and wire bar coating to achieve a thickness of $75-80 \mathrm{~nm}$, as determined with a Dektak 6M profilometer. Film drying kinetics was monitored in situ by a CCD camera and automated image analysis, and 'film formation time' was estimated based on 
cessation of colour change (Fig. S1, ESI $\dagger$ ). The films were then placed into an evaporation vacuum chamber for $25 \mathrm{~nm}$ of calcium and $100 \mathrm{~nm}$ of aluminium deposition through a 6-pixel mask (each pixel area is $0.045 \mathrm{~cm}^{2}$ ) respectively. Selected samples were illuminated under a fluorescent lamp prior to electrode deposition, corresponding to 'light' conditions, while some 'dark' control films were kept in the dark conditions; both in a $\mathrm{N}_{2}$ glove box. The deposited devices were annealed at $80{ }^{\circ} \mathrm{C}$ while the device performance was measured. Annealing temperature was measured and calibrated using a Kane-May KM330 temperature sensor. The devices current densityvoltage $(J-V)$ characteristics were measured using a Xenon lamp at AM 1.5 solar illumination (Oriel Instruments) calibrated to a silicon reference cell with a Keithley 2400 source meter. A fluorescent lamp was used as light source, with light irradiance $\left(\approx 10 \mathrm{~mW} \mathrm{~cm}^{-2}\right)$ and wavelength distribution calibrated with photospectrometer (StellarNet EPP2000).

\section{Morphology and neutron reflectivity studies}

$\mathrm{SiO}_{x}$ substrates were purchased from Compart Technology and cleaned with $\mathrm{N}_{2}$ before deposition of the same PCDTBT:PC ${ }_{60} \mathrm{BM}$ solution by SC and WBC techniques. For few selected substrates, $35 \mathrm{~nm}$ of PEDOT:PSS layers were spun coated on $\mathrm{SiO}_{x}$ substrates before solution deposition. Film thicknesses were confirmed by profilometry. The blend films were illuminated and annealed at $80{ }^{\circ} \mathrm{C}$ and $140{ }^{\circ} \mathrm{C}$ in a $\mathrm{N}_{2}$ glove box. The same fluorescent lamp was applied as the light source. The morphology of the films was measured with a reflection optical microscopy (Olympus BX 41M), equipped with an XY stage and CCD camera (AVT Marlin). The surface topography of annealed films was measured with atomic force microscopy (Innova, Bruker AXS) in tapping-mode, using super sharp TESP-SS tips.

\section{Results and discussion}

Fig. 1 illustrates our processing route, including the deposition of active layer (PCDTBT:PC ${ }_{60} \mathrm{BM}$ ) with $\mathrm{SC}$ and $\mathrm{WBC}$ techniques along with a light treatment (and dark control) prior to an evaluation of thermal stability. The device employs a conventional architecture ITO/PEDOT:PSS/PCDTBT: $\mathrm{PC}_{60} \mathrm{BM} / \mathrm{Ca} / \mathrm{Al}$ together with an optimized solvent, polymer : fullerene ratio and solution

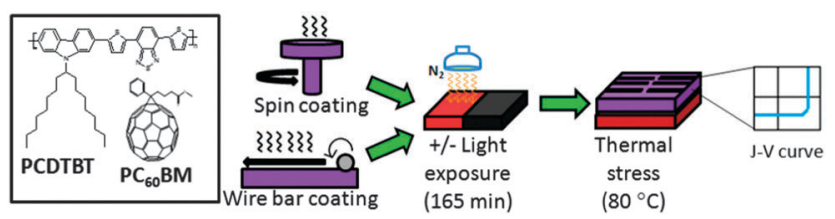

Fig. 1 Schematic representation of processing PCDTBT:PC ${ }_{60} B M$ blend with different coating techniques (SC and $\mathrm{WBC}$ ) and light treatment. Chemical structures of PCDTBT and $\mathrm{PC}_{60} \mathrm{BM}$ are shown on the left box. Modest illumination ( $<10 \mathrm{~mW} \mathrm{~cm}^{-2}$ ) is irradiated on film for a constant duration of 165 minutes prior electrode (Ca/Al) vacuum deposition. The devices and films without and with illumination are designated as "dark" (black colour) and "light" (red colour) conditions respectively in this study. The performance $(J-V$ curve) of the fabricated devices is measured under $80{ }^{\circ} \mathrm{C}$ thermal stress. concentration, as described in the Experimental section, and following previous work; ${ }^{42,43}$ these parameters are therefore kept constant throughout this study.

Our first observation is that WBC films exhibit a higher average drying time (13-15 s), compared to SC films (around $5 \mathrm{~s}$ ) to achieve a similar film thickness of $75-80 \mathrm{~nm}$ PCDTBT: $\mathrm{PC}_{60} \mathrm{BM}$ blend film. ${ }^{42}$ Drying time was estimated by film colour (Fig. S1, $\mathrm{ESI}^{\dagger}$ ); this trend is expected due to the rapid solution removal during the initial stages of SC, followed by drying. The volume required for $\mathrm{WBC}$ is only $15 \mu \mathrm{L}$, compared to $35 \mu \mathrm{L}$ for $\mathrm{SC}$, due to the waste created during the spinning process, which is a major asset of the former processing route.

\section{Device performance and stability}

The performance of typical devices fabricated with SC and WBC techniques, in the absence of prior light processing, is shown in Fig. 2a (procedures detailed in the Experimental section). Although these coating techniques involve different film formation mechanisms, the initial performance of these typical devices achieved using the SC and WBC techniques are identical for this system within measurement uncertainty (average PCE of $5.20 \pm 0.2 \%$ and $5.22 \pm 0.2 \%$ for SC and WBC respectively). These similar performances can be understood as a result of a compromise between $J_{\mathrm{SC}}$ and $\mathrm{FF}: 9.82 \mathrm{~mA} \mathrm{~cm} \mathrm{~cm}^{-2}$ and 0.59 for SC and $9.29 \mathrm{~mA} \mathrm{~cm}^{-2}$ and 0.61 for $\mathrm{WBC}$, for the devices shown. The differences in $J_{\mathrm{SC}}$ and FF did not correlate with variations in film thickness $( \pm 5 \mathrm{~nm})$ and the $V_{\text {OC }}$ achieved in both devices is the same $(0.93 \mathrm{~V})$ and typical for optimized PCDTBT:PC ${ }_{60} \mathrm{BM}$ systems. ${ }^{42}$

From the UV-visible absorption and polymer photoluminescence (PL) quenching measurements (Fig. S2 and S3, ESI $\dagger$ ), we find that films fabricated by SC and WBC have similar optical absorption, indicating similar PCDTBT:PC ${ }_{60} \mathrm{BM}$ compositions and similar PL quenching, showing similar polymer exciton quenching efficiencies, indicative of a similarly intermixed system. This verification is needed to ensure no composition bias is introduced during film deposition. The SC devices do however exhibit higher External Quantum Efficiencies (EQE) (Fig. S4, ESI $\dagger$ ), consistent with their higher $J_{\text {SC }}$ (Fig. 2a). On the other hand, the higher FF attained for the WBC devices suggests a better percolation pathway for efficient charge transport in the morphology obtained by WBC.

These devices, along with their light-processed analogues, were thermally annealed at $80{ }^{\circ} \mathrm{C}$ for 1000 hours in the dark in a glove box, and their room temperature performance measured periodically under a simulated AM 1.5 irradiation. These thermal stress PCE results are summarized in Fig. 2b. 'Light processed' devices, were exposed to $\approx 10 \mathrm{~mW} \mathrm{~cm}^{-2}$ white light for $165 \mathrm{~min}$, prior to thermal annealing, following a procedure reported previously ${ }^{20,21}$ and illustrated in Fig. 1. We have found this modest and brief light pre-treatment to yield no significant loss of the initial device performance, ${ }^{20,21}$ and that the thermal ageing profile remained unchanged before and after top electrode deposition, ${ }^{21}$ (by contrast with the top electrode interfacial degradation reported by McGehee and co-workers, ${ }^{44}$ for $60 \mathrm{~h}$ under 1 sun conditions). For the current devices, we recorded a 

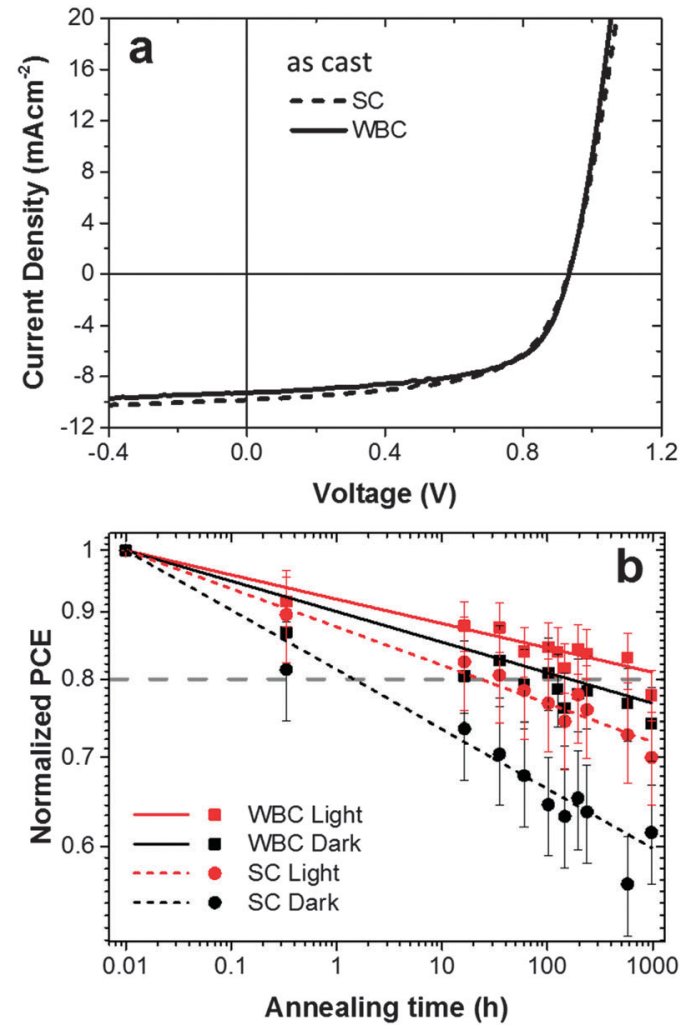

Fig. 2 (a) Current density (J)-voltage ( $V$ ) curves for typical PCDTBT: $\mathrm{PC}_{60} \mathrm{BM}$ blend devices processed with $\mathrm{SC}$ and WBC (prior to light processing) exhibiting PCE of $5.33 \%$ and $5.26 \%$ respectively (b) log : log plot of normalized PCE vs. annealing time during thermal stress at $80^{\circ} \mathrm{C}$ for devices fabricated via SC and WBC under dark and light processing conditions.

modest $(\approx 5 \%)$ drop in initial device performance, attributed to minor glove box contamination over the period of these experiments. The PCEs obtained are averaged over 3 pixels each from two different devices. We note that the PCE variation (obtained from 6 distinct measurements) of SC devices is somewhat larger than that of WBC devices (approximately by $\approx 10-20 \%$ ); this might be caused by the faster kinetics of SC film formation, but further work would be required to establish statistically significant deviations.

The decays of the device PCEs in the four conditions shown in Fig. $2 \mathrm{~b}$ are mainly due to changes in $\mathrm{FF}$ and $J_{\mathrm{SC}}$ (data not shown). In all cases, the drop in device efficiency is, within measurement uncertainty, well described by a single power law decay, compatible with a single degradation process (and timescale).

We quantify relative device thermal stability by estimating the OSC 'lifetimes' corresponding to a $20 \%$ drop of the initial PCE under $80{ }^{\circ} \mathrm{C}$ annealing. The SC device without prior light exposure ('dark' control) degrades to $80 \%$ of its initial performance after only $3 \mathrm{~h}$ under thermal stress. Compared to this control, all the other processing conditions resulted in significant improvements in stability. SC devices exhibit an approximate 10 fold stability improvement after light processing, consistent with our previous findings of photo-induced $\mathrm{PC}_{60} \mathrm{BM}$ oligomerization. ${ }^{20,21}$ Interestingly, WBC devices, even in the absence of light processing; exhibit approximately 20 times thermal stability enhancement compared to the control SC devices. This improvement is further enhanced by light processing by a factor of around 10, bringing it to a total of approximately $200 \times$ lifetime enhancement for light processed WBC devices over dark processed SC devices in dark conditions, with a $20 \%$ reduction of PCE only being observed after 1000 hours of thermal stress at $80{ }^{\circ} \mathrm{C}$. Similar lifetime enhancements are obtained with different degradation criteria, e.g. by defining the time associated with a $10 \%$ drop in efficiency. The devices manufactured by WBC and light processing have thus substantially improved stability compared to both SC and WBC dark counterparts.

By comparing the relative magnitudes of lifetime enhancement, we find that there is a compound effect of solution casting technique and photo-induced oligomerization, well above a simple additive rule. A possible explanation for this synergy is that fullerene oligomerization reactions are strongly concentration-dependent and not directly proportional to light intensity due to a partial of back-reaction from excited triplet states. ${ }^{45}$ An enhancement of WBC device stability after light treatment could indicate a higher $\mathrm{PC}_{60} \mathrm{BM}$ concentration available for oligomerization thereby restricting the degradation of performance. However, UV-vis data (Fig. S2, ESI $\dagger$ ) confirm that the average PCDTBT and $\mathrm{PC}_{60} \mathrm{BM}$ composition remains similar regardless of solution casting technique. We therefore hypothesize that longer drying times involved in WBC may result in enhanced fullerene segregation, which locally raises fullerene concentration and, in turn, increase the propensity for photooligomerization.

\section{Morphological stability}

In order to investigate the stability enhancement of devices fabricated by WBC, the film nanostructure was investigated by optical and AFM as well as specular neutron reflectivity (NR). To allow a direct comparison with OSC performance data, the active layers (supported by PEDOT:PSS, but without electrode deposition) were annealed at $80{ }^{\circ} \mathrm{C}$ for $1 \mathrm{~h}$, the AFM results are shown in Fig. 3. As expected, we observed the formation of nano-sized $\mathrm{PC}_{60} \mathrm{BM}$ crystals $(\sim 100 \mathrm{~nm})^{46}$ on the $\mathrm{SC}$ film on PEDOT:PSS (Fig. 3a). Evidently, below the $T_{\mathrm{g}}$ of both neat polymer and fullerene phases, the composite films enable sufficient $\mathrm{PC}_{60} \mathrm{BM}$ mobility (corroborated by interdiffusion ${ }^{41}$ and morphological studies ${ }^{21}$ ) to yield nano-sized aggregation. These nano-crystals do not form when the film is illuminated prior to thermal annealing (Fig. 3b), which we have rationalized in terms of the suppressed nucleation associated with photoinduced oligomerization. ${ }^{21}$ Our recent results on nano-sized $\mathrm{PC}_{60} \mathrm{BM}$ crystallization suppression by chemically synthesized $\mathrm{PC}_{60} \mathrm{BM}$ dimers within the active layer ${ }^{41}$ supports this interpretation. Unexpectedly, no nano-crystals are observed on blends produced by WBC on PEDOT:PSS substrates with or without light processing, as shown in Fig. $3 \mathrm{c}$ and d. The films have similar topography and roughness, with maximum amplitude of $10.3 \mathrm{~nm}$ and $11.9 \mathrm{~nm}$ in 'dark' and 'light' conditions respectively. Negligible micron-sized crystallization is observed for all samples on PEDOT:PSS ( $c f$. optical microscopy data in Fig. S5 and $\mathrm{S} 7, \mathrm{ESI} \dagger$ ), interpreted as due to a bias towards nano-sized 


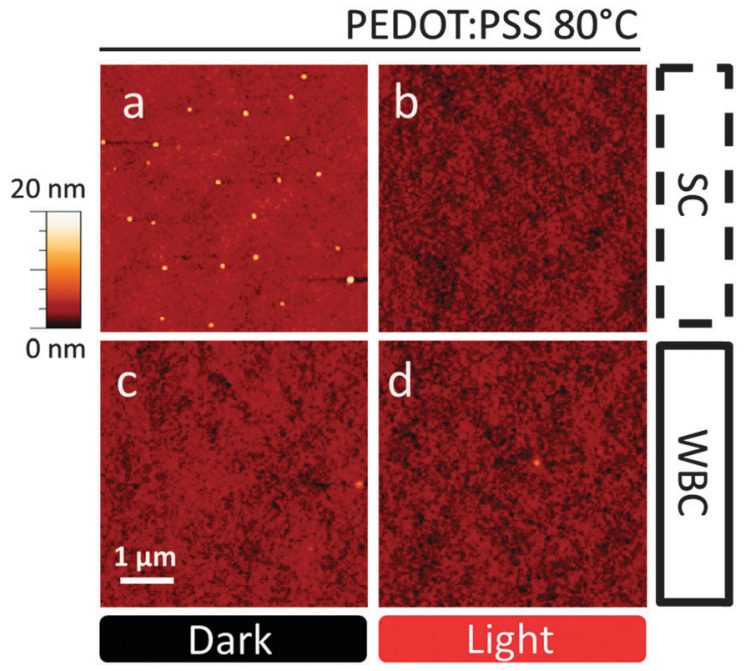

Fig. 3 AFM images of PCDTBT:PC ${ }_{60} B M$ blend on PEDOT:PSS substrate annealed at $80^{\circ} \mathrm{C}$ for I h. Films cast by (a) and (b) SC and (c) and (d) WBC and processed without (a) and (c) and with (b) and (d) prior light exposure.

crystal formation on PEDOT:PSS in the context of $\mathrm{PC}_{60} \mathrm{BM}$ 's competitive bimodal crystallization. ${ }^{27,29}$ The inhibition of nano-crystal formation with WBC coating and light processing correlates qualitatively with our device thermal stability results, whereby SC device performance in dark conditions is the least stable under thermal stress.

Intriguingly, we find that morphological studies of thermally induced $\mathrm{PC}_{60} \mathrm{BM}$ crystallization of the same blends when cast onto $\mathrm{SiO}_{x}$ substrates, as used in several previous studies, ${ }^{20,21,32,47-51}$ does not correlate with our device stability data. Representative optical micrographs of SC and WBC films annealed for $1 \mathrm{~h}$ at $140{ }^{\circ} \mathrm{C}$, with or without prior light treatment, are shown in Fig. 4 . As cast films on $\mathrm{SiO}_{x}$ are uniform in all cases (Fig. S6, ESI $\dagger$ ) in agreement with previous findings, ${ }^{21}$ and annealing at $80{ }^{\circ} \mathrm{C}$ does not suffice to induce crystallization, as seen by AFM and optical microscopy. Thermal annealing of thin blend films supported by $\mathrm{SiO}_{x}$ substrates above glass transition temperature at $140{ }^{\circ} \mathrm{C}$ results exclusively in micron-sized fullerene crystals, ${ }^{20,21,32,47-51}$ in contrast to nano-sized on PEDOT:PSS substrates. ${ }^{21}$ The number density of micron-scale crystals in WBC films is now considerably higher (Fig. 4c) than in SC films (Fig. 4a) for 'dark' control blends. Partial suppression of micron-sized $\mathrm{PC}_{60} \mathrm{BM}$ crystallization is observed for both SC and WBC films upon prior light exposure, as shown in Fig. 4b and d, and the crystal number density remains higher in the latter. While morphology and OSC performance are often correlated, and specifically large scale crystallization is generally associated with poor performance, these results on $\mathrm{SiO}_{x}$ show the opposite trend with device PCE stability between WBC and SC devices. We find this to be a significant observation as, owing to the good optical contrast and simplicity sample preparation, $\mathrm{SiO}_{x}$ substrates are often employed in surrogate optical microscopy morphological stability studies for OSCs under thermal stress; annealing temperatures higher than typical operating temperatures are also often employed to facilitate phase identification. $^{20,40}$ In this case, we show that morphological

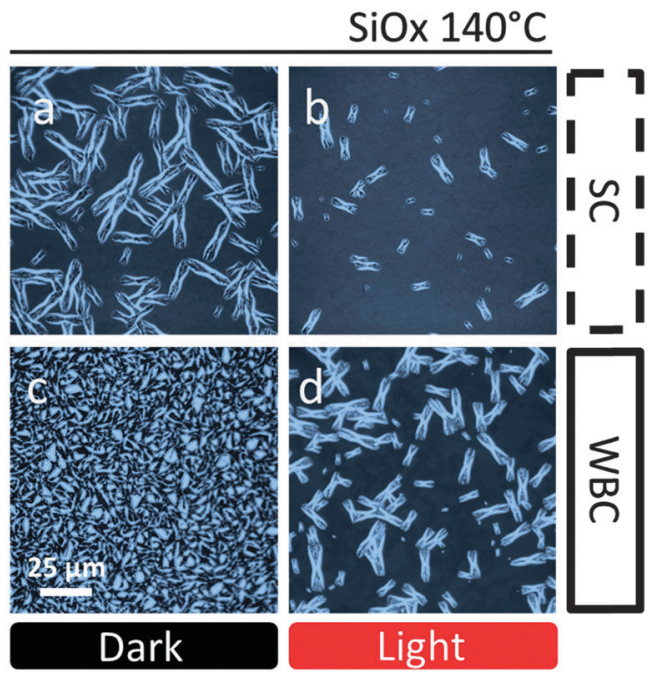

Fig. 4 Optical microscope images of PCDTBT:PC ${ }_{60} B M$ blend on PEDOT:PSS substrate annealed at $140{ }^{\circ} \mathrm{C}$ for I hour. Films deposited by (a) and (b) SC and (c) and (d) WBC and processed without (a) and (c) and with (b) and (d) prior light exposure.

results for annealed $\mathrm{SiO}_{x}$ supported films are inversely correlated with OSC stability. However, we do find a positive correlation between nano-sized crystallization and the loss of device performance under thermal stress, at the same annealing temperature $\left(80^{\circ} \mathrm{C}\right)$ and for films supported by the same substrate (PEDOT:PSS), as shown by Fig. 2 and 3.

In order to rationalize these findings, we turn to NR to evaluate the film composition depth profiles for both SC and WBC techniques, light exposure and substrate types ( $\mathrm{SiO}_{x}$ and PEDOT:PSS). Our hypothesis is that $\mathrm{PC}_{60} \mathrm{BM}$ stratification during film formation and the effectiveness of lightinduced oligomerization at high fullerene concentration may, jointly and individually, contribute to thermal stability. We recall that the topochemical criteria for photo-induced fullerene $2+2$ cyclo-addition requires parallel carbon double bond alignment of adjacent fullerenes and fullerene proximity below $4.2 \AA^{52}$ In first approximation, photo-oligomerization is therefore more likely to be satisfied at a higher fullerene concentration, thus upon a stronger segregation, suggesting that local $\mathrm{PC}_{60} \mathrm{BM}$ concentration at both interface is likely to be critical to film and device thermal stability.

NR was employed to measure the scattering length density (and thus composition) profile of thin films along the direction orthogonal to the film surface (i.e. momentum transfer along $q_{z}$, the vertical direction). We investigate the influence of SC and WBC on the film depth profile, the role of the substrate (namely, $\mathrm{SiO}_{x}$ and PEDOT:PSS) and that of moderate light exposure (and 'dark' control). Fig. 5a compares the reflectivity and depth profile of as cast films deposited on PEDOT:PSS by WBC and SC. As cast depth profile of PCDTBT:PC ${ }_{60} \mathrm{BM}$ deposited on PEDOT:PSS using SC technique has been previously studied using $\mathrm{NR}^{53,54}$ where $\mathrm{PC}_{60} \mathrm{BM}$ enrichment at the top interface, with diminishing concentration towards the substrate interface, are observed. Our SC results (bottom row in Fig. 5a) generally 

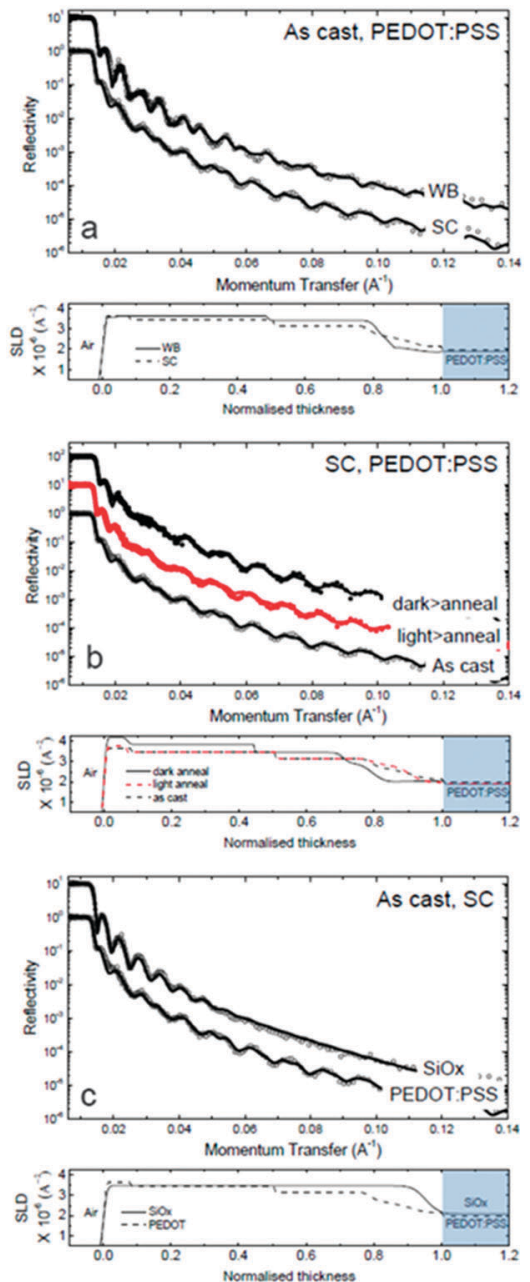

Fig. 5 Neutron reflectivity data of PCDTBT:PC ${ }_{60} B M$ system: (a) as cast SC and WBC films on PEDOT:PSS substrate; (b) SC films on PEDOT:PSS substrate in 'dark' and 'light' conditions after thermal annealing at $80{ }^{\circ} \mathrm{C}$ for 1 hour; (c) as cast SC films on PEDOT:PSS and $\mathrm{SiO}_{x}$ substrates.

agree with previous reports. Compared to SC, we find that WBC films exhibit higher $\mathrm{PC}_{60} \mathrm{BM}$ enrichment at the air interface as well as more $\mathrm{PC}_{60} \mathrm{BM}$ depleted at the substrate interface (top data in Fig. 5a), consistent with the longer time scale for film formation and thus component segregation. This finding is also consistent with the higher device $\mathrm{FF}$, with the $\mathrm{PC}_{60} \mathrm{BM}$ enrichment at the active layer-cathode interface likely to improve charge collection as shown in Fig. 2a. This segregation is not detrimental to overall device performance as similar PCE values were obtained for devices fabricated with both techniques. Also, such segregation correlates well with expected higher efficiency for photo-oligomerization and thus the observed superior device thermal stability upon light exposure. Indeed, we observe the illuminated WBC condition offers the most stable device performance of all four conditions tested (Fig. 2b). In short, our results suggest that the longer drying time associated with WBC result in enhanced compositional segregation, and thus a film depth profile which is more thermally stable and more susceptible to photo-oligomerization compared to SC films.
In agreement with our previous findings on polystyrene(PS): $\mathrm{C}_{60},{ }^{55}$ we find that light exposure does not alter the film reflectivity profiles, and thus the composition depth profile, of polymer:fullerene films. Here we show the scattering length density ( $\mathrm{SLD}) / \mathrm{PC}_{60} \mathrm{BM}$ composition depth profiles of lightprocessed spun cast films also remain largely unchanged upon $80{ }^{\circ} \mathrm{C}$ annealing (red filled data), compared to as cast films (black unfilled data) as shown in Fig. 5b. This robustness to annealing illustrates the role of $\mathrm{PC}_{60} \mathrm{BM}$ photo-oligomerization in OSC film stability and contrasts with the depth profile changes of films annealed without prior illumination (black filled data) ('dark' SC). Indeed, we find enhanced $\mathrm{PC}_{60} \mathrm{BM}$ surface segregation in 'dark' SC films upon annealing and, in AFM which probes the lateral structure, we observe the formation of $\mathrm{PC}_{60} \mathrm{BM}$ nano-sized crystals (Fig. 3a).

We finally compare the composition depth profile of films supported by PEDOT:PSS and $\mathrm{SiO}_{x}$ substrates and a more uniform $\mathrm{PC}_{60} \mathrm{BM}$ profile in the latter, compared to the former (Fig. $5 \mathrm{c}$ ). This stratification is mediated by the lower surface energy of PEDOT:PSS $\left(\approx 47 \mathrm{mN} \mathrm{m}^{-1}\right)$, compared to $\operatorname{SiO}_{x}\left(\approx 73 \mathrm{mN} \mathrm{m}^{-1}\right) .{ }^{56}$ The device thermal instability appears to correlate with the formation of nano-sized crystals in the active layer, whose inhibition (e.g. by light-induced oligomerization of $\left.\mathrm{PC}_{60} \mathrm{BM}\right)$ yields OSCs with enhanced thermal stabilities. The presence of a trivial fraction of $\mathrm{PC}_{60} \mathrm{BM}$ oligomers (10-20\%) appears to effectively suppress nucleation and thus film crystallization. ${ }^{20,21,41}$

Evidently, WB films form over longer timescales compared to SC films, which appears to yield enhanced film composition segregation as shown by NR, which we believe hinders $\mathrm{PC}_{60} \mathrm{BM}$ diffusion. Light exposure further improves both WBC and SC devices yielding solar cells with enhanced lifetimes. This synergistic effect is particularly significant for WBC cells, whose lifetime improvement appears to be approximately multiplicative (instead of additive, for example) with respect to SC 'dark' devices.

\section{Conclusions}

In summary, we examine the morphology and performance of PCDTBT: $\mathrm{PC}_{60} \mathrm{BM}$ organic solar cells fabricated by two significant solution casting techniques: wire bar coating (WBC), compatible with large scale manufacturing, and spin coating (SC), well established for lab-scale fabrication and employed for most OSC research. We find that both WBC and SC solar cells yield similar initial performance, despite slight variations of $J_{\mathrm{SC}}$ and FF, as measured by PCE $(\approx 5 \%)$. WBC utilizes a much lower solution volume than that required by SC of equivalent active layer films. Further, we find that WBC cells exhibit improved device thermal stabilities, measured over $1000 \mathrm{~h}$ annealing at $80{ }^{\circ} \mathrm{C}$, which appears to stem from enhanced $\mathrm{PC}_{60} \mathrm{BM}$ segregation, towards the top interface during deposition, which is likely due to longer film drying timescales. To the best of our knowledge, this is the longest time frame for thermal stability investigated with this system. We show that both WBC and SC cells respond favorably to a light processing step prior to thermal annealing, which increases device lifetime due to a 
morphological stabilization caused by $\mathrm{PC}_{60} \mathrm{BM}$ photooligomerization. The overall PCE lifetimes for WBC light processed solar cells is found to be nearly 200 times longer compared to conventional SC devices (manufactured without light processing).

We found that widely used correlations between morphological stability and device lifetime can be misleading if morphological studies are not performed at the same temperature and on the same device substrate, due to impact of the substrate in film vertical segregation and lateral morphology. For example, the morphological results of WBC and $\mathrm{SC}$ on $\mathrm{SiO}_{x}$ actually suggest the opposite trend for OSC thermally stability, since WBC films are found to result in a much greater fullerene crystal number density at $140{ }^{\circ} \mathrm{C}$ on $\mathrm{SiO}_{x}$ but yield OSC with much improved thermal stability on PEDOT:PSS. In this case, morphological studies of micron-sized crystallization on $\mathrm{SiO}_{x}$ thus provide neither insight into OSC morphology on PEDOT:PSS nor prediction for its thermal stability and lifetime.

We do find that OSC lifetime under thermal stress correlates with nano-sized crystal formation on PEDOT:PSS at the relevant annealing temperature. Polymer-fullerene demixing is wellknown to impact OSC performance ${ }^{57}$ and we find that WBC results in more stable devices compared to SC. The timescales for film formation can be tuned by employing a controlled atmosphere, mixed solvents and additives, or by vapor annealing, opening possibilities for further improvement. Similarly the light-induced stabilization depends on wavelength, exposure duration and temperature, of which only one condition was explored in this work, resulting in substantial device lifetime enhancement. There are therefore realistic prospects that optimization of these processing parameters will enable further improvements of thermal stability of OSCs and relieve a major bottleneck for their current commercial viability.

\section{Acknowledgements}

The authors thank the EPSRC (EP/I019278/1 and KTS, DPF funding for ZL and HCW) and the Welsh government (Sêr Cymru) as well as the EU project CHEETAH for financial support. The authors also thank Marie-Beatrice Madec (Solvay SA), and Pabitra Shakya and Shahid Ashraf (Imperial) for help in device fabrication. We are grateful to the Institut Laue Langevin (ILL), Grenoble for beamtime and Dr P. Gutfreund (ILL) and Dr A. Guilbert (Imperial) for experimental support.

\section{Notes and references}

1 S. H. Park, A. Roy, S. Beaupre, S. Cho, N. Coates, J. S. Moon, D. Moses, M. Leclerc, K. Lee and A. J. Heeger, Nat. Photonics, 2009, 3, U297-U295.

2 F. Liu, Y. Gu, J. W. Jung, W. H. Jo and T. P. Russell, J. Polym. Sci., Part B: Polym. Phys., 2012, 50, 1018-1044.

3 G. Li, R. Zhu and Y. Yang, Nat. Photonics, 2012, 6, 153-161.

4 M. C. Scharber and N. S. Sariciftci, Prog. Polym. Sci., 2013, 38, 1929-1940.
5 F. C. Krebs, in Organic photovoltaics 6, ed. Z. H. Kafafi and P. A. Lane, SPIE Proceedings Series, International Society for Optical Engineering, Bellingham, 2005, vol. 5938, pp. 234-244.

6 Z. He, C. Zhong, S. Su, M. Xu, H. Wu and Y. Cao, Nat. Photonics, 2012, 6, 591-595.

7 F. C. Krebs, Sol. Energy Mater. Sol. Cells, 2009, 93, 394-412. 8 K. Norrman, A. Ghanbari-Siahkali and N. B. Larsen, Annu. Rep. Prog. Chem., Sect. C: Phys. Chem., 2005, 101, 174-201.

9 T. Wang, N. W. Scarratt, H. Yi, A. D. F. Dunbar, A. J. Pearson, D. C. Watters, T. S. Glen, A. C. Brook, J. Kingsley, A. R. Buckley, M. W. A. Skoda, A. M. Donald, R. A. L. Jones, A. Iraqi and D. G. Lidzey, Adv. Energy Mater., 2013, 3, 505-512.

10 J. Ouyang, T. F. Guo, Y. Yang, H. Higuchi, M. Yoshioka and T. Nagatsuka, Adv. Mater., 2002, 14, 915-918.

11 C. E. Murphy, L. Yang, S. Ray, L. Yu, S. Knox and N. Stingelin, J. Appl. Phys., 2011, 110, 093523.

12 Y. Galagan, I. G. de Vries, A. P. Langen, R. Andriessen, W. J. H. Verhees, S. C. Veenstra and J. M. Kroon, Chem. Eng. Process., 2011, 50, 454-461.

13 C. R. McNeill, Energy Environ. Sci., 2012, 5, 5653-5667.

14 X. Zhang, J. F. Douglas and R. L. Jones, Soft Matter, 2012, 8, 4980-4987.

15 M. Campoy-Quiles, T. Ferenczi, T. Agostinelli, P. G. Etchegoin, Y. Kim, T. D. Anthopoulos, P. N. Stavrinou, D. D. C. Bradley and J. Nelson, Nat. Mater., 2008, 7, 158-164.

16 C. Koidis, S. Logothetidis, A. Ioakeimidis, A. Laskarakis and C. Kapnopoulos, Org. Electron., 2013, 14, 1744-1748.

17 B. Dan, G. C. Irvin and M. Pasquali, ACS Nano, 2009, 3, 835-843.

18 W. Ma, C. Yang, X. Gong, K. Lee and A. J. Heeger, Adv. Funct. Mater., 2005, 15, 1617-1622.

19 G. Li, Y. Yao, H. Yang, V. Shrotriya, G. Yang and Y. Yang, Adv. Funct. Mater., 2007, 17, 1636-1644.

20 Z. Li, H. C. Wong, Z. Huang, H. Zhong, C. H. Tan, W. C. Tsoi, J. S. Kim, J. R. Durrant and J. T. Cabral, Nat. Commun., 2013, 4, 2227.

21 H. C. Wong, Z. Li, C. H. Tan, H. Zhong, Z. Huang, H. Bronstein, I. McCulloch, J. T. Cabral and J. R. Durrant, ACS Nano, 2014, 8, 1297-1308.

22 B. A. Collins, J. R. Tumbleston and H. Ade, J. Phys. Chem. Lett., 2011, 2, 3135-3145.

23 X. Yang, J. K. J. van Duren, M. T. Rispens, J. C. Hummelen, R. A. J. Janssen, M. A. J. Michels and J. Loos, Adv. Mater., 2004, 16, 802-806.

24 A. Swinnen, I. Haeldermans, M. vande Ven, J. D'Haen, G. Vanhoyland, S. Aresu, M. D'Olieslaeger and J. Manca, Adv. Funct. Mater., 2006, 16, 760-765.

25 C. H. Woo, B. C. Thompson, B. J. Kim, M. F. Toney and J. M. J. Fréchet, J. Am. Chem. Soc., 2008, 130, 16324-16329.

26 E. Verploegen, R. Mondal, C. J. Bettinger, S. Sok, M. F. Toney and Z. Bao, Adv. Funct. Mater., 2010, 20, 3519-3529.

27 L. Zheng, J. Liu and Y. Han, Phys. Chem. Chem. Phys., 2013, 15, 1208-1215.

28 J. J. Richards, A. H. Rice, R. D. Nelson, F. S. Kim, S. A. Jenekhe, C. K. Luscombe and D. C. Pozzo, Adv. Funct. Mater., 2013, 23, 514-522. 
29 D. Mon, A. M. Higgins, D. James, M. Hampton, J. E. Macdonald, M. B. Ward, P. Gutfreund, S. Lilliu and J. Rawle, Phys. Chem. Chem. Phys., 2015, 17, 2216-2227.

30 E. Voroshazi, B. Verreet, T. Aernouts and P. Heremans, Sol. Energy Mater. Sol. Cells, 2011, 95, 1303-1307.

31 R. De Bettignies, J. Leroy, M. Firon and C. Sentein, Synth. Met., 2006, 156, 510-513.

32 B. J. Kim, Y. Miyamoto, B. Ma and J. M. J. Fréchet, Adv. Funct. Mater., 2009, 19, 2273-2281.

33 J. W. Rumer and I. McCulloch, Materials Today, 2015, DOI: 10.1016/j.mattod.2015.04.001.

34 B. Liu, R.-Q. Png, L.-H. Zhao, L.-L. Chua, R. H. Friend and P. K. H. Ho, Nat. Commun., 2012, 3, 1321.

35 G. Griffini, J. D. Douglas, C. Piliego, T. W. Holcombe, S. Turri, J. M. J. Fréchet and J. L. Mynar, Adv. Mater., 2011, 23, 1660-1664.

36 J. Kesters, P. Verstappen, J. Raymakers, W. Vanormelingen, J. Drijkoningen, J. D'Haen, J. Manca, L. Lutsen, D. Vanderzande and W. Maes, Chem. Mater., 2015, 27, 1332-1341.

37 L. Derue, O. Dautel, A. Tournebize, M. Drees, H. Pan, S. Berthumeyrie, B. Pavageau, E. Cloutet, S. Chambon, L. Hirsch, A. Rivaton, P. Hudhomme, A. Facchetti and G. Wantz, Adv. Mater., 2014, 26, 5831-5838.

38 J. Peet, J. Y. Kim, N. E. Coates, W. L. Ma, D. Moses, A. J. Heeger and G. C. Bazan, Nat. Mater., 2007, 6, 497-500. 39 P. Zhou, Z.-H. Dong, A. M. Rao and P. C. Eklund, Chem. Phys. Lett., 1993, 211, 337-340.

40 F. Piersimoni, G. Degutis, S. Bertho, K. Vandewal, D. Spoltore, T. Vangerven, J. Drijkoningen, M. K. Van Bael, A. Hardy, J. D’Haen, W. Maes, D. Vanderzande, M. Nesladek and J. Manca, J. Polym. Sci., Part B: Polym. Phys., 2013, 51, 1209-1214.

41 B. C. Schroeder, Z. Li, M. A. Brady, G. C. Faria, R. S. Ashraf, C. J. Takacs, J. S. Cowart, D. T. Duong, K. H. Chiu, C.-H. Tan, J. T. Cabral, A. Salleo, M. L. Chabinyc, J. R. Durrant and I. McCulloch, Angew. Chem., Int. Ed., 2014, 53, 12870-12875.

42 T.-Y. Chu, S. Alem, P. G. Verly, S. Wakim, J. Lu, Y. Tao, S. Beaupre, M. Leclerc, F. Belanger, D. Desilets, S. Rodman, D. Waller and R. Gaudiana, Appl. Phys. Lett., 2009, 95, 063304.
43 S. Wakim, S. Beaupre, N. Blouin, B.-R. Aich, S. Rodman, R. Gaudiana, Y. Tao and M. Leclerc, J. Mater. Chem., 2009, 19, 5351-5358.

44 T. Heumueller, W. R. Mateker, I. T. Sachs-Quintana, K. Vandewal, J. A. Bartelt, T. M. Burke, T. Ameri, C. J. Brabec and M. D. McGehee, Energy Environ. Sci., 2014, 7, 2974-2980.

45 J. Wang, J. Enevold and L. Edman, Adv. Funct. Mater., 2013, 23, 3220-3225.

46 We note the formation of nano-sized crystal was found to be dependent upon PCDTBT batch.

47 J. Jo, S.-S. Kim, S.-I. Na, B.-K. Yu and D.-Y. Kim, Adv. Funct. Mater., 2009, 19, 866-874.

48 M. A. Ruderer, S. Guo, R. Meier, H.-Y. Chiang, V. Körstgens, J. Wiedersich, J. Perlich, S. V. Roth and P. MüllerBuschbaum, Adv. Funct. Mater., 2011, 21, 3382-3391.

49 O. Oklobia and T. S. Shafai, Sol. Energy Mater. Sol. Cells, 2013, 117, 1-8.

50 Z. Wu, T. Song, Y. Jin and B. Sun, Appl. Phys. Lett., 2011, 99, 143306.

51 S. Khiev, L. Derue, G. Ayenew, H. Medlej, R. Brown, L. Rubatat, R. C. Hiorns, G. Wantz and C. DagronLartigau, Polym. Chem., 2013, 4, 4145-4150.

52 A. M. Rao, M. Menon, K.-A. Wang, P. C. Eklund, K. R. Subbaswamy, D. S. Cornett, M. A. Duncan and I. J. Amster, Chem. Phys. Lett., 1994, 224, 106-112.

53 J. W. Kingsley, P. P. Marchisio, H. Yi, A. Iraqi, C. J. Kinane, S. Langridge, R. L. Thompson, A. J. Cadby, A. J. Pearson, D. G. Lidzey, R. A. L. Jones and A. J. Parnell, Sci. Rep., 2014, 4, 5286.

54 P. A. Staniec, A. J. Parnell, A. D. F. Dunbar, H. Yi, A. J. Pearson, T. Wang, P. E. Hopkinson, C. Kinane, R. M. Dalgliesh, A. M. Donald, A. J. Ryan, A. Iraqi, R. A. L. Jones and D. G. Lidzey, Adv. Energy Mater., 2011, 1, 499-504.

55 H. C. Wong, A. M. Higgins, A. R. Wildes, J. F. Douglas and J. T. Cabral, Adv. Mater., 2013, 25, 985-991.

56 C. He, D. S. Germack, R. Joseph Kline, D. M. Delongchamp, D. A. Fischer, C. R. Snyder, M. F. Toney, J. G. Kushmerick and L. J. Richter, Sol. Energy Mater. Sol. Cells, 2011, 95, 1375-1381. 57 B. A. Collins, E. Gann, L. Guignard, X. He, C. R. McNeill and H. Ade, J. Phys. Chem. Lett., 2010, 1, 3160-3166. 